\title{
conjugar-se com o (que é) outro na experiência do filosofar
}

\author{
paula ramos de oliveira ${ }^{1}$ \\ universidade estadual paulista júlio de mesquita filho, brasil
}

resumo

Torna-se cada vez mais um desafio situar-nos para além de nossas palavras, quase sempre repetidas e esvaziadas. Esse texto apresenta e pensa duas novas possibilidades de experiências do Grupo de Estudos e Pesquisas "Filosofia para Crianças" (GEPFC - FCLAr CNPq) que pretendem enfrentá-lo, "desconcertando" pensamentos e leituras de mundo: a primeira inventa outro modo de ler o "Abecedário de Deleuze", transitando com palavras e imagens (desenhos); e a segunda coloca crianças e adultos filosofando juntos. "Desconcertar o pensamento" é procurar caminhos diferentes para que possamos nos abrir ao novo, ao (que é) outro, fazendo exercícios que nos permitam realizar experiências de pensamento, alargando os sentidos de nossa existência. Inspirado em Benjamin vemos a experiência filosófica como comportando três degraus (móveis): o musical (em que ela é composta), o arquitetônico (em que ela é construída) e o têxtil (em que ela é tecida). Andar pelos degraus da experiência filosófica é conjugar-se com o (que é) outro. Um sujeito que filosofa há que poder ser outro (e não ser palavra de poder para o outro) e saber do outro, saber-se outro e saber-se com o outro (e não apequenar o outro com nossos saberes porque assim, inclusive, apequenamos a nós mesmos). Mas há infinitas conjugações e delas nascem gestos que são modos de dizer (linguagem). Quando amoroso, esse gesto-linguagem cria um espaço novo entre os dois pontos não coincidentes e é essa novidade que abre espaço para a experiência filosófica distanciando-nos de saberes e poderes que nos apequenam.

palavras-chave: filosofar; crianças; adultos; imagens; palavras.

\section{conjugarse con el (que es) otro em la experiencia do filosofar}

resumen

Se hace cada vez más difícil ponernos a nosotros mismos más allá de nuestras palabras, a menudo repetidas y vacías. Este artículo presenta y piensa dos nuevas posibilidades de experiencias del Grupo del Estudios e Investigaciones "Filosofía para Niños" (GEPFC FCLAr - CNPq) que tienen la intención de hacer frente a esa dificultad, "desconcentrando" pensamientos y lecturas del mundo: la primera elabora otra manera de leer el "Abecedario de Deleuze", transitando con palabras e imágenes (dibujos); y la segunda pone los niños y adultos a filosofar juntos. "Desconcentrar el pensamiento" es buscar caminos diferentes para que podamos abrirnos a lo nuevo, a lo (que es) otro, haciendo ejercicios que nos permitan realizar experiencias de pensamiento, extendiendo los sentidos de nuestra existencia. Inspirados en Benjamin miramos la experiencia filosófica como un conjunto de tres escalones (móviles): el musical (en que ella es compuesta), el arquitectónico (en que ella es construida) y el textil (donde ella es tejida). Caminar por los escalones de la experiencia filosófica es conjugarse con lo (que es) otro. Un sujeto que filosofa debe poder ser otro (y no palabra de poder para otro), saber del outro, saberse outro y saber con el otro (y no empequeñecer el otro con nuestro saber, porque así, también, empequeñecemos a nosotros mismos). Pero, hay un sinfín de conjugaciones y de ellas nacen gestos que son maneras de decir (lenguaje). Cuando amoroso, ese gesto-lenguaje crea un espacio nuevo entre los dos puntos no

\footnotetext{
${ }^{1}$ E-mail: paula-ramos@uol.com.br.
} 
coincidentes y es esta novedad que deja espacio para la experiencia filosófica, alejándonos de saberes y poderes que nos empequeñecen.

palabras-clave: filosofar; niños; adultos; imágenes; palabras.

\section{conjugate with what the other is according to the experience of philosophising}

abstract

It turns to be more and more challenging to place ourselves beyond our own words, which are often repeated and emptied. This text presents and thinks two new possibilities related to experiences of the Group of Studies and Researches "Philosophy for Children" (GEPFC/FCLAr/CNPq) which intends to face this challenge by "mixing up the thinking" and reading of the world. The first invents another way of reading "The Alphabet of Deleuze", dealing with words and images (drawings). The second one puts children and adults making philosophy together. "Mixing up thinking" is to look for different ways, making it possible to open ourselves to the new, to what the other is, doing exercises that permit us to conduct experiences with/of thinking, consequently widening the senses of our existence. Based on Benjamin we can see the philosophical experience consisting of three steps (moving): musical (in which it is composed), arquitectural (in which it is constructed) and textile (in which it is woven). Walking up the steps of the philosophical experience is conjugating with what the other is. A subject who philosophizes must be capable of being the other (not to be a word of power for the other), and get to know the other, be the other and be with the other (not to make the other smaller with our knowledge because this way we make us smaller as well). However, there are endless conjugations from which gestures come out as ways of saying (language). As far as it is loving, this gesture-language creates a new space between two non-coincident points and this is novelty that opens room for the philosophical experience taking us for from knowledge and power which make us smaller.

keywords: philosophize; children; adults; images; words. 
conjugar-se com o (que é) outro na experiência do filosofar

\begin{abstract}
“Descubro cada vez mais que o paraíso são os outros. Vi num livro para adultos. Li só isso: o paraíso são os outros." (MÃE, 2014, p. 12).
\end{abstract}

\title{
introdução
}

O outro é maior que o mundo.

Tenho o outro dentro de mim.

Portanto, sou maior que o mundo.

Mas tudo isso se conjuga de infinitas maneiras...

\section{1. duas experiências com(o) novos inícios: a busca por "desconcertar o pensamento"}

\author{
ATENÇÃO, DEGRAUS!
}

O trabalho em uma boa prosa tem três degraus: um musical, em que ela é composta, um arquitetônico, em que ela é construída e, enfim, um têxtil, em que ela é tecida. (BENJAMIN, 1987, p. 27).

Em tempos de empobrecimento das experiências e em contexto de administração do pensamento, tal como formulam os filósofos frankfurtianos, promover experiências torna-se cada vez mais um desafio. Como então realizar experiências de pensamento para além de nossas palavras quase sempre repetidas e esvaziadas?

O Grupo de Estudos e Pesquisas “Filosofia para Crianças” (GEPFC - FCLAr CNPq), em atividade desde 1998, sob a minha coordenação, atualmente experimenta duas novas possibilidades de experiência que pretendem enfrentar esse desafio e é acerca delas, e com elas, que esse texto quer começar.

O que ambas buscam é o que chamaremos de "desconcertar o pensamento", procurando caminhos diferentes para que possamos nos abrir ao novo. Buscamos essa novidade como quem faz exercícios que querem se realizar como experiência e ampliação do pensamento, alargando os sentidos de nossa existência. Procuramos novos sentidos e não novas verdades. Como sujeitos que querem filosofar, queremos experimentar quem somos - e não o que achamos que deveríamos ser quando vemos outros sujeitos que filosofam -, pois, entendemos, qualquer relação com o que é outro 
fica muito empobrecida quando não olhamos para nós mesmos e desrespeitamos o que estamos sendo. De fato, essa relação assim constituída não permite fazer-se como experiência.

\subsection{Experiência 1: desenhar com as palavras de Deleuze}

A primeira delas, que teve início no ano de 2015 e se estende até hoje, consiste em certa leitura do “O Abecedário de Deleuze” (2001). Há muitas leituras possíveis, mas também muitos modos de se ler. Podemos ler sempre do mesmo modo e ainda assim produzir leituras diferentes em cada uma das vezes. Mas, e quando experimentamos modos diferentes de ler, será que também ampliamos modos de produzir leituras? Queríamos saber.

Decidimos então o seguinte percurso: para cada letra teríamos uma leitura individual e outra coletiva. Como "desconcertaríamos" essas leituras? A proposta foi a de que cada um de nós traria a sua leitura, mas partindo de outra forma expressiva: o desenho. Queríamos nos desalojar das velhas formas de trazer nossas leituras, com o objetivo de permitirmos outras elaborações. E assim foi. Cada um chegava com um desenho. No grupo fazíamos a leitura coletiva e íamos comentando, com palavras, o que íamos lendo. Ao final, ou simplesmente quando alguém quisesse, mostrávamos nossa leitura com o desenho. Desta forma, as palavras mais nossas, nossas primeiras palavras, não surgiam de palavras, mas do desenho que, este sim, havia surgido de outras palavras. Era - e ainda é - um exercício totalmente diferente para nós. Fazíamos essa transição entre imagens e palavras (o que, por enquanto, chamaremos de duas formas expressivas ou de duas linguagens) e tudo ficava diferente.

É muito comum em aulas de filosofia, e também fora delas (por exemplo, na arte), as palavras virem das imagens. Também sabemos que o artista produz imagens e dentro delas há ideias - sejam elas explícitas ou não, conscientes ou não. O que propomos é um outro modo de ler, não igual aos artistas, mas talvez inspirado neles. Como colocar em imagens o que pensamos quando lemos o pensamento de outro? Como expressar o que ficou mais forte em nós sem as palavras? E depois nova transição: junto com o desenho vem uma narração de todo o processo que o seu autor pensou, de todo o seu pensamento em processo. Não o que lemos de Deleuze, mas 
sim o que fomos capazes (não no sentido de suficiência ou insuficiência) de ler quando lemos Deleuze. Foi assim que decidimos operar com outra transição: atrás da folha desenhada escrevíamos o processo da palavra ao desenho e do desenho à palavra. Com essa experiência do pensamento tornou-se inevitável perguntar: Qual a força da imagem na criação de palavras e a das palavras na criação de imagens? A pergunta permanece em nós.

\subsection{Experiência 2: crianças e adultos juntos no filosofar}

Ao longo dos anos o GEPFC sempre se dedicou às aulas de filosofia com crianças. Fomos à escola pública (EMEF Waldemar Saffiotti) onde realizamos um projeto de filosofia e xadrez, a um abrigo residencial ("Lar Cristo Rei”) onde ligamos filosofia e contação de histórias, e à Escola Municipal de Dança Iracema Nogueira onde pudemos experimentar a filosofia em um ambiente voltado às artes, graças ao projeto especial que tal escola desenvolve. Todas essas atividades ocorreram na cidade de Araraquara - SP.

Nos últimos anos nos dedicamos a um projeto ("Ler Ciência") do SESC São Carlos com a Secretaria Municipal de Educação dessa cidade. Nele, ao longo de três anos, elaboramos atividades para que um conceito científico (sempre de um pesquisador brasileiro), tratado por meio da literatura, pudesse ser desenvolvido na sala de aula com a filosofia. Assim, além do contato com os professores, fomos nos últimos dois anos do projeto a todas as salas de aula das escolas municipais, levando um exemplo de filosofar.

O ano de 2015, por diversas razões, foi um ano de pausa. No final dele, senti vontade de oferecer encontros de filosofia para filhos ou conhecidos de alunos, funcionários e professores de nossa faculdade. Resolvi postergar essa atividade, experimentar antes um encontro parecido na própria disciplina de Filosofia para Crianças, oferecida como obrigatória no segundo semestre do terceiro ano do Curso de Pedagogia da Faculdade de Ciências e Letras de Araraquara. Os alunos, que já haviam participado de diversas experiências de pensamento na disciplina e que se encontravam no final do semestre, agora poderiam "ver" como as crianças fariam essa experiência. 
Mas então algumas questões se colocaram. Para o que havíamos vivido na disciplina, não seria bom que de um lado ficassem os observadores (os adultos) e de outro os observados (as crianças). E fui pensando até o dia em que os encontros ocorreriam em como poderíamos proceder. Haveria um encontro na turma da tarde e outro na turma da noite - ambas com cinquenta alunos, o que dificultava a participação de todos.

Quando as crianças chegaram, junto com seus responsáveis, me pareceu, um pouco intuitivamente, que poderia ser interessante colocar crianças e adultos juntos, mas somente com os adultos que haviam trazido crianças, pois assim não as intimidaríamos com tantos outros que poderiam "abafar" suas vozes, especialmente por serem adultos, mas também por já estarem habituados a essa atividade. E assim começamos.

Com o decorrer do encontro fui envolvendo os que estavam fora da roda e perguntei se poderíamos também inclui-los. A resposta foi positiva e tudo fluiu com muita naturalidade, acontecendo de forma semelhante na segunda turma. Percebi que os alunos da disciplina tiveram a sensibilidade necessária para não apequenarem as crianças - minha maior preocupação - e algo novo de fato ocorreu. Crianças e adultos filosofaram juntos naquelas turmas. Criou-se um lugar especial onde coubesse esse encontro com pessoas de diferentes idades. E encerramos a disciplina e o semestre com essa nova abertura em nossas vidas, com esse outro jeito de estar junto.

Chegou o ano de 2016 e decidimos que o GEPFC teria reuniões alternadas: uma continuando o trabalho com Deleuze e outra com crianças e adultos filosofando juntos. Quais crianças? Filhas de membros do grupo ou de outros alunos e ex-alunos. À princípio levaríamos a mesma palavra estudada para esse encontro multietário e, de fato, começamos com a palavra em que estávamos: alegria (jolie). Mas depois entendemos que essa não era uma boa ideia porque alguns já teriam lido algo de e/ou sobre Deleuze antes e outros não.

Até o momento fizemos apenas duas reuniões: uma com o tema "alegria" e outra com o tema "amor". Em ambas fomos da imagem às palavras, seguindo parte do mesmo trânsito das reuniões em que lemos Deleuze. O tema "alegria" começou 
com um pedido para que cada um de nós desenhasse o que nos deixava alegre. Todos os desenhos foram colocados no chão e então cada um escolheu o que quis e em seguida começamos a dizer o que víamos nele. Depois é que vínhamos a saber de quem era. No segundo dia várias fotos foram espalhadas no chão e cada um deveria tentar achar uma em que não identificasse o amor. Caso não achasse, escolheria alguma que quisesse. Em seguida, as pessoas que haviam encontrado fotos "sem amor", comentavam seus motivos. A próxima (dia 28/04/2016) será sobre o tema "brincar". A sugestão surgiu de uma criança e nos pareceu que será um belo exercício para uma experiência multietária.

Essas duas experiências, aqui brevemente descritas, também produziram uma diferença de cenários: na primeira incluímos lápis de cor, giz de cera, canetinhas e folhas sulfites; na segunda as crianças coloriram a universidade, andando junto com seus responsáveis de mãos dadas, talvez com tanta expectativa quanto nós.

\section{Na nossa prosa há três degraus para subir e descer!}

As pessoas são diferentes. Aprecio muito que o sejam. Fico a pensar se me acharão diferente também. Adoraria que achassem. Ser tudo igual é característica de azulejo na parede e, mesmo assim, há quem misture.

Eu sou a favor de uma meia de cada cor. Adoro cores. A minha mãe diz: organize. Significa que acha que eu baralho demasiado. (MÃE, 2014, p. 11).

Ao tratar das histórias que envolvem o projeto "Em Caxias a filosofia encaixa?" (KOHAN; OLARIETA, 2012), Walter Kohan descreve “os passos para andar o filosofar" propondo a compreensão da experiência de filosofia como uma composição:

Falamos de "composição" de uma experiência, e não de "estrutura", porque queremos aproximar a proposta metodológica dos trabalhos que fazem os artistas. Os materiais, as técnicas, estão a serviço do músico ou do pintor, mas o resultado do que eles fazem ultrapassa a técnica, os materiais e os instrumentos. Sugerimos esses materiais não como uma receita, mas como uma matéria plástica para sobre ela começar a compor nossa própria obra. (KOHAN, 2012, p. 19).

Bela imagem esta porque esse material dedica-se à organização e prática filosófica por parte dos professores que participam do projeto e cada um, de fato, faz essa composição da experiência filosófica de um modo particular. 
No que diz respeito à nossa "obra", enfocamos a necessidade que víamos de "desconcertar" o pensamento. Desconcertar é também descompor, o que significa que na nossa composição queríamos descompor o pensamento (torná-lo outro do que vem sendo) - mas não a experiência!

Retomemos, agora, a epígrafe com Benjamin e vejamos os três degraus que podem fazer dessas experiências uma "boa prosa": o musical (degrau em que elas são compostas), o arquitetônico (degrau em que elas são construídas) e o têxtil (degrau em que elas são tecidas).

Podemos então dizer que o que acabamos de descrever de nossa "obra" (a composição da experiência filosófica) é o nosso degrau musical cuja singularidade é produzir uma música que procura ter sua própria afinação pela busca de sua harmonia em acordes dissonantes.

Uma experiência tem também uma arquitetura. Arquiteto é aquele que constrói espaços. Em nossas experiências somos nós os arquitetos a construir espaços para que, inclusive, haja espaços para novas construções. Tem-se a construção de um espaço para a experiência quando se abre um espaço para que algo possa ser construído.

Abrimos espaço para o que é outro: outro modo de ler (trânsito das palavras às imagens e das imagens às palavras) e outro modo de filosofar (com pessoas de idades diferentes). A construção desse espaço que se abre ao outro abre espaço para construções outras. Esse é mais um dos degraus da experiência filosófica.

Cada experiência acontece de uma maneira porque cada experiência (se) tece também de uma maneira. Em toda experiência há algo que vai se tecendo. Esse é a dimensão têxtil do que fazemos quando filosofamos. As nossas experiências são tecidas por imagens e palavras (como chegamos ao pensamento de um jeito outro) e por pessoas (nos fazemos em relação ao que é outro).

Esses são os passos que usamos para compor a nossa experiência filosófica porque filosofamos procurando o que é outro em um contexto em que está muito difícil - e talvez cada vez mais - fazer experiências intelectuais originais. Com a palavra "original" queremos dizer não apenas do novo, antes impensado, mas da importância de cuidar da outra face do original que é a nossa capacidade de gerar 
cópias a partir dele, abafando justamente o que é novo. Assim, andamos de modo lúdico para exercitarmos um desocupar do nosso hábito de gerar cópias, lendo (e, portanto, pensando e escrevendo porque vivemos em relação com essas leituras) o que já foi lido no mundo, sem diálogo efetivo com o que somos e, por isso, cada vez mais com menos autoria. E menos autoria significa menos capacidade de realizarmos experiências.

\section{3. andar pelos degraus conjugando-se com o (que é) outro}

As pessoas que amam estão sempre com ar de urgência, porque elas têm saudade quando não estão acompanhadas e sentem uma euforia bonita quando estão juntas.

Eu acho que as pessoas apaixonadas sentem saudade mesmo quando estão juntas, porque ficam sempre a olhar umas para outras pasmadas como se fosse a primeira vez. Até como se fosse a primeira vez que vissem sapos, neve, cataratas, aqueles peixes voadores, jacarés, prédios com mais de trinta andares ou o Miguel a enrolar os olhos. (MÃE, 2014, p. 17).

$\mathrm{O}$ que acontece quando andamos pelos degraus em uma experiência filosófica? Simplesmente vamos (nos) conjugando com o que é outro. O que fazemos nós quando estamos diante do outro? E onde está, quem é e o que faz esse outro quando o temos diante de nós? O que sabemos do outro? O outro se diz em quais línguas?

\section{1. o (que é) outro}

\section{Premissa 1: O outro é maior que o mundo}

Somos atravessados por modos de ler o mundo. $\mathrm{O}$ próprio mundo é leitura e nos atravessa enquanto leitura. Cada um é leitura de mundo e cada leitura é um mundo. Vamos nos constituindo por essas leituras (FREIRE, 1989) e com elas escrevemos o mundo. E o que isso significa? Que lemos também a nossa escrita do mundo porque nele nos inscrevemos. Somos ele. Estamos nele. Tudo ao mesmo tempo. Só nos pensamos dentro dele e, no entanto, ele continua fora de nós. É outro que nós. É outro para nós. E o outro é maior que o mundo simplesmente porque há muita grandeza dentro de cada um de nós. 


\section{Premissa 2: Tenho o outro dentro de mim}

No mundo de cada um de nós há muito espaço para caber o que é outro. Às vezes o que vem do outro cabe no que estamos sendo e, nesse caso, podemos tecer com essa espécie de igualdade ou diferença autênticas experiências. Deixo o outro entrar e torno-me, ao mesmo tempo, diferente do que vinha sendo e mais quem eu sou. Torno-me outro porque tenho dentro de mim essa possibilidade, esse espaço para ser outro. Tenho o outro dentro de mim. Esse outro pode ser o que ainda não sou ou o que já sou sem saber que sou, que ainda me é desconhecido. Mas em todos os casos tenho o outro dentro de mim, tenho o que é outro dentro de mim.

\section{conclusão: portanto, sou maior que o mundo}

Como acolhemos o que é "outro que nós", sendo que ainda temos também esse "o que é outro"? Como nos relacionamos como o que difere do que estamos sendo?

Em cada relação há um modo específico e, portanto, singular de acolher o diferente. Mas não poderia o que é outro comportar um certo "igual" que apenas não seria aquilo que estava sendo? Se sim, que igualdade seria esta? O que nos liga a alguém? O que nos liga a nós mesmos? Vivemos para cada dia o sabermos e é por isso que o mundo que temos em cada um de nós é maior, cada vez maior, que o mundo todo! Quando vamos em direção a outros mundos possíveis, nosso mundo aumenta, fica maior.

Com o outro acontece o mesmo. De modo que cada um de nós se transforma por um novo mundo que se inscreve em nós, mas também pelo que outros mundos leem de nós. Já não somos o que éramos antes de cada encontro e, paradoxalmente, somos também mais "nós mesmos". Nunca deixaremos de ser singulares, ainda que plurais, ainda que compostos por tantos mundos quantos couberem em nós.

Entre dois mundos que se escrevem, pelas leituras que deles se fazem, algo se inscreve. Algo se gesta. Dentro de nós há algo que aos poucos se abre para acolher esse o (que é) outro em um gesto de hospitalidade, que como escolha que é, é também liberdade. 
Esse gesto que nasce entre o que somos e o (que é) outro é uma inflexão, um acontecimento, um modo de dizer... Ainda que possa vir desacompanhado de palavras, um gesto nasce de palavras cheias de sentidos - sentidos que se dizem ao outro como gesto; gesto que se sente também como palavra, gesto que se traduz como linguagem, porque é um modo de dizer, em qualquer linguagem.

[...] que a linguagem não é apenas algo que temos e sim que é quase tudo o que somos, que determina a forma e a substância não só do mundo, mas também de nós mesmos, de nosso pensamento e de nossa experiência, que não pensamos a partir de nossa genialidade e sim a partir de nossas palavras, que vivemos segundo a língua que nos faz, da qual estamos feitos. E aí o problema não é só o que é aquilo e o que é que podemos dizer, mas também, e sobretudo, como dizemos: o modo como diferentes maneiras de dizer nos colocam em diferentes relações com o mundo, com nós mesmos e com os outros. (LARROSA, 2014, p.58).

Gesto é linguagem. Linguagem é gesto. Quando amoroso, esse gestolinguagem permite que se crie um espaço novo entre os dois pontos não coincidentes e essa novidade abre espaço para a experiência filosófica.

Esse gesto-linguagem amoroso, entre o que somos e aquilo ou aquele que difere do que somos, é, segundo o que pensamos, o que abre espaço para ver o mundo com o olhar pasmado de toda primeira vez, capaz de alargar nossa existência por novos sentidos que traz, nos afastando de certos saberes, poderes e verdades que insistem ocupar os degraus por onde caminha qualquer pensamento que teima em não se tornar experiência nenhuma, muito menos filosófica, que é só e pura repetição.

\section{4. o gesto-linguagem amoroso nas duas experiências}

As pessoas mais velhas, quando não são um casal, dão beijos pequenos. As pessoas novas costumam dar beijos mais longos, cheios de paciência. [...] Tenho muitas dúvidas. Quando me apaixonar, dizem-me, fico logo esclarecida. Aguardarei desconfiada. Não aceito as coisas à pressa. Preciso de pensar. (MÃE, 2014, p.18).

Que saberes, poderes e verdades circulam entre os mais jovens e os mais velhos nas mais diversas experiências de vida? Quando a questão é a diferença de idade, tudo parece mais claro (embora não seja), mas se pensarmos nas possíveis leituras de textos de Deleuze (ou de qualquer outro autor) teremos os que são mais velhos e os que são mais jovens nela, pois cada um tem as mais diversas relações com a filosofia, com os textos de Deleuze, com os seus comentaristas, com a história da 
filosofia, etc. Assim, um ponto que talvez una as duas experiências do GEPFC é uma tentativa de começar a procurar o que é outro através de uma composição que busque descompor essas diferenças (de idades e de leituras). Trata-se então de buscar exercícios para além de possíveis hierarquias, tais como "os adultos e as crianças", "os que sabem mais e os que sabem menos”, "os que leram mais de um autor e os que leram menos", etc.

Um segundo ponto diz respeito a uma relação do pensamento com suas formas expressivas. Benjamin afirma, e com ele concordamos: "É sabido que o dizer não é apenas a expressão do seu pensamento, mas também a sua realização." (BENJAMIN, 1987, p. 268). É exatamente assim que entendemos a filosofia: como um pensamento que vem sempre acompanhado de sua força expressiva e que por ela se realiza. Cada força expressiva se diz com um jeito particular. A linguagem escolhida para ocupar o âmago do filosofar é e sempre foi a palavra. Tentamos com as duas experiências outros exercícios com a palavra. Em primeiro lugar o desenho não é uma habilidade comumente solicitada em um grupo de estudos e pesquisas em filosofia. Sendo assim, rompemos com uma certa estrutura de poder com a palavra ao romper com ela como um veículo inicial do pensamento. Em segundo lugar, o modo de entrar no texto também se modificou, pois em um desenho é ao mesmo tempo uma representação que se diz de acordo (com suas possibilidades e limites) com sua forma expressiva. Qual é o centro do texto? O centro é também o mais importante? O que ficou para mim-leitor como central no texto? Qual é o centro do texto em mim? Qual é o centro de mim no texto? O início de um desenho e o modo como ele vai se desenhando mostra como o (nosso) centro vai se ligando aos outros pontos do texto. É uma leitura bastante autoral e que dialoga com as outras e também, claro, com o próprio texto (com Deleuze). E então o mais importante não é se somos mais novos ou mais velhos nesse modo de ler e de dialogar. Esse tipo de leitura desconcerta o pensamento porque ir da palavra ao desenho e do desenho à palavra é um exercício bem diferente do que ir da palavra escrita à outra palavra (escrita ou falada). Nele o pensamento se realiza não só como palavra, mas também como imagem. E ainda em um espaço de cruzamento que estamos bem longe de compreender. Foucault (1988) fez um intenso e inspirador exercício de leitura de um 
cruzamento da imagem e da palavra que aparece na famosa pintura de Magritte, chamada "Isto não é um cachimbo" - título também da obra do filósofo.

Quanto ainda ao segundo ponto na experiência 2, começar com imagem é também um jeito diferente de aproximar crianças e adultos, talvez já muito separados pela palavra, pelo poder, pelo poder da palavra e pela palavra (de) poder. Quem é mais jovem ou mais velho no desenho? Quem está mais próximo dele? Ou com fotos (no caso do segundo encontro): quem é mais jovem ou mais velho ao olhar uma foto para encontrar algo nela? Quem terá que se exercitar mais de outro modo? Rompe-se então com um modo de circulação de saberes e de poderes, abrindo um lugar para outra relação com a palavra e com o outro.

O que mostram os pontos que destacamos? Que encontrar o que é outro implica outra enunciação e em outra língua ainda a ser inventada na qual possamos ter espaços onde verdades cedam lugar à produção de sentidos em que nenhuma dimensão do humano venha a ser apequenada.

\section{uma palavra-imagem final}

Como nossas relações são mediadas pela linguagem, e como a linguagem permite muitas formas de enunciação, dissemos que pensamos a linguagem como aquilo que permite "um gesto que diz", seja com palavras ou não. É, portanto, algo que se gesta para nascer (como um modo de dizer), que vai em direção a algo ou alguém (uma inflexão), e que se faz em ato (um acontecimento, compreendido aqui como algo singular e que irrompe uma única vez nesse encontro que temos com o que é outro).

Esse gesto-linguagem sobe e desce os três degraus compondo uma experiência filosófica que, aos poucos, vai instituindo novas conjugações com o (que é) outro.

Um sujeito que filosofa há que poder ser outro (e não ser palavra de poder para o outro) e saber do outro, saber-se outro e saber-se com o outro (e não apequenar o outro com nossos saberes porque assim, inclusive, apequenamos a nós mesmos) para conseguir perceber novos sentidos - e não verdades - que podem ser tecidos em nossa existência, costurados de forma mais rara e autoral, com a firmeza, calma e leveza de quem se aproxima cada vez mais de quem se é: o (que é) outro. 
O trabalho sobre nós mesmos na experiência do filosofar é, então, a um só tempo musical, arquitetônico e têxtil, mas todos esses degraus precisam ser móveis porque escolhemos um caminhar lúdico e amoroso por eles: subimos e descemos, pisando em todos os lados, vertical e horizontalmente, conjugando-nos ao (que é) outro.

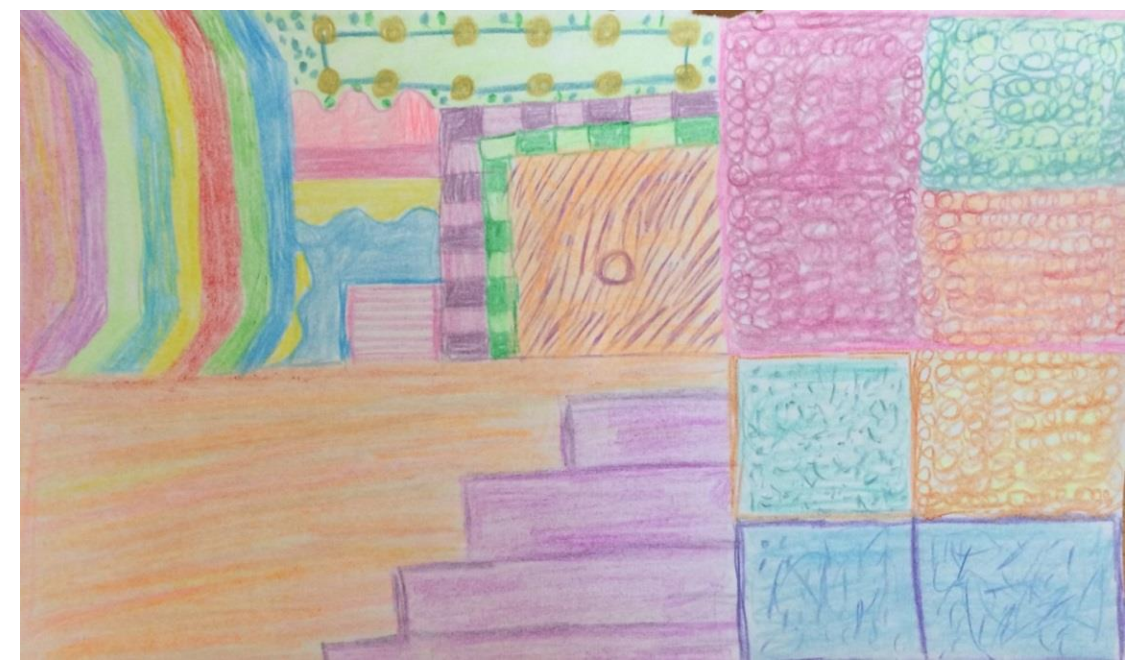

(desenho da autora)

\section{referências}

BENJAMIN, Walter. Rua de mão única. Tradução de Rubens Rodrigues Torres Filho e José Carlos Martins Barbosa. $2^{\mathrm{a}}$ ed. São Paulo: Brasiliense, 1987. (Obras escolhidas, v.2).

DELEUZE, Gilles. O abecedário de Gilles Deleuze. Entrevista com G.Deleuze. Editoração: Brasil, Ministério da Educação, TV Escola, 2001. Paris: Éditions Montparnasse, 1997, VHS, 459min. FOUCAULT, Michel. Isto não é um cachimbo. Tradução de Jorge Coli. Rio de Janeiro: Paz e Terra, 1988.

FREIRE, Paulo. O ato de ler o mundo. In: FREIRE, Paulo. A importância do ato de ler: em três artigos que se completam. São Paulo: Autores Associados; Cortez, 1989. p. 9-14.

KOHAN, Walter Omar. Palavras, passos e nomes para um projeto. In: KOHAN, Walter Omar; OLARIETA, Beatriz Fabiana. A escola pública aposta no pensamento. Belo Horizonte: Autêntica, 2012. p. 13-49.

LARROSA, Jorge. Uma língua para conversação. Tradução Cristina Antunes e João Wanderley Geraldi. In: LARROSA, Jorge. Tremores: escritos sobre experiência. Belo Horizonte: Autêntica, 2014. p. 57-72.

MÃE, Valter Hugo. O paraíso são os outros. Ilustrações de Nino Cais. São Paulo: Cosac Naify, 2014. 